\title{
Trisomy 13
}

INSERM

\section{Source}

INSERM. (1999). Orphanet: an online rare disease and orphan drug data base. Trisomy 13. ORPHA:3378

Trisomy 13 is a chromosomal anomaly caused by the presence of an extra chromosome 13 and is characterized by brain malformations (holoprosencephaly), facial dysmorphism, ocular anomalies, postaxial polydactyly, visceral malformations (cardiopathy) and severe psychomotor retardation. 